Provided for non-commercial research and education use. Not for reproduction, distribution or commercial use.

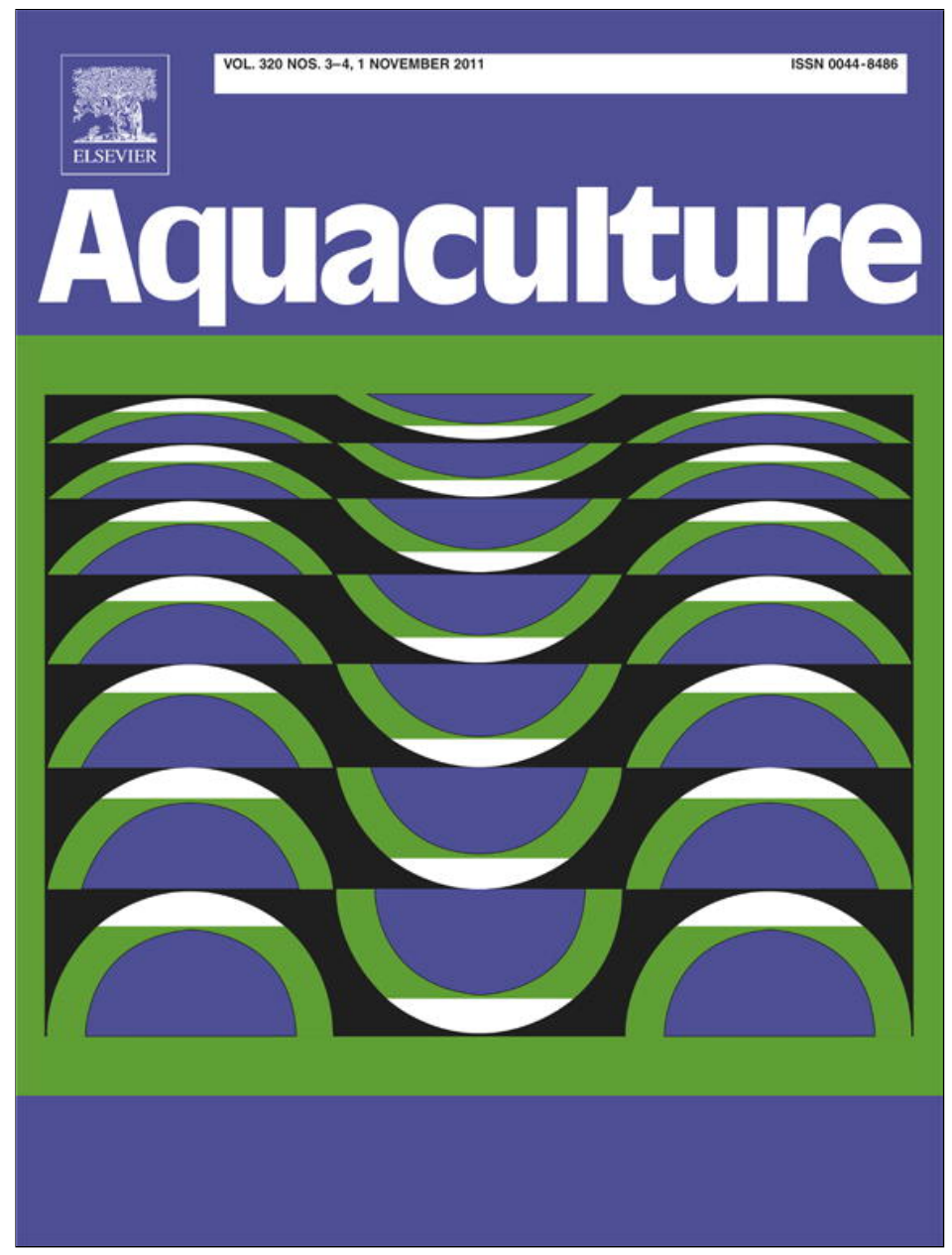

This article appeared in a journal published by Elsevier. The attached copy is furnished to the author for internal non-commercial research and education use, including for instruction at the authors institution and sharing with colleagues.

Other uses, including reproduction and distribution, or selling or licensing copies, or posting to personal, institutional or third party websites are prohibited.

In most cases authors are permitted to post their version of the article (e.g. in Word or Tex form) to their personal website or institutional repository. Authors requiring further information regarding Elsevier's archiving and manuscript policies are encouraged to visit:

http://www.elsevier.com/copyright 


\title{
Use of a mathematical model to describe the epidemiology of Lepeophtheirus salmonis on farmed Atlantic salmon Salmo salar in the Hardangerfjord, Norway
}

\author{
George Gettinby ${ }^{a}$, Chris Robbins ${ }^{b}$, Fiona Lees ${ }^{a}$, Peter A. Heuch ${ }^{c}$, Bengt Finstad ${ }^{d}$, \\ Ragnild Malkenes ${ }^{\text {e, }}$ Crawford W. Revie ${ }^{\mathrm{f}, *}$ \\ a Mathematics and Statistics, University of Strathclyde, Richmond Street, Glasgow G1 1XH, UK

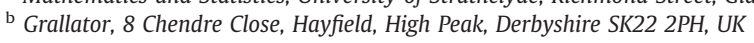 \\ c National Veterinary Institute, Oslo, Norway \\ d Norwegian Institute for Nature Research, Trondheim, Norway \\ e Hardanger Fish Health Network, Tysnes, Norway \\ ${ }^{\mathrm{f}}$ Atlantic Veterinary College, University of PEI, Charlottetown, PE C1A 8A5, Canada
}

\section{A R T I C L E I N F O}

\section{Article history:}

Received 24 June 2010

Received in revised form 10 March 2011

Accepted 16 March 2011

Available online 23 March 2011

\section{Keywords:}

Mathematical model

Salmon farms

Lepeophtheirus salmonis

Norway

Multiple treatment types

\begin{abstract}
A B S T R A C T
Infestation patterns of the sea louse Lepeophtheirus salmonis from 44 salmon farms in the Hardangerfjord on the south-west coast of Norway over the period 2004 to 2007 were assimilated to create 20-month production cycle profiles for spring and autumn stocked generations. The timing and frequency of in-feed and bath treatments to control sea lice associated with these profiles was considered. Spring and autumn stocked farms were observed to have different patterns of sea lice counts on salmon during the first and second years of production. Spring stocked sites experienced increasing infestation toward the end of the first year and on average counts remained elevated thereafter, whereas autumn stocked sites averaged lower sea lice counts throughout most of the production cycle until the latter part of the second year when these escalated rapidly. In-feed treatments were the predominant form of sea lice control in the first half of the production cycle on spring stocked farms, whereas bath treatments were used exclusively in the second half of the production cycle; a very similar pattern of therapeutant use was observed on autumn stocked farms.

Results using the SLiDESim (Sea Lice Difference Equation Simulation) infection model and a range of biological and production parameters showed that modelling resulted in a better fit to the mobile lice profiles for autumn stocked farms compared to spring stocked farms. Some features of the mobile lice profiles were not captured by the infection model such as the oscillation of the population between months 11 and 18 of the production cycle on spring stocked farms, and a large peak observed in month 19 on autumn stocked farms. Before modelling can be used to evaluate optimal treatment strategies or other management interventions there remains a need to more clearly understand the underlying biological processes associated with the dynamics of sea lice infestations in the Hardangerfjord.
\end{abstract}

(c) 2011 Elsevier B.V. All rights reserved.

\section{Introduction}

Sea lice infections are a serious worldwide threat to indigenous wild salmon populations and the sustainability of farmed salmon production units (Krkošek et al., 2007; Costello, 2009). In recent years the control of lice in European and North and South American salmon producing countries has become critical with many countries adopting strategic regional sea lice control programmes (Heuch et al., 2005; Revie et al., 2009). Not only can lice have a negative impact on farmed fish, in terms of product quality and farm productivity, but increasingly lice infected salmon farms may be a source of Lepeophtheirus salmonis infestation for

* Corresponding author at: Department of Health Management, Atlantic Veterinary College, University of Prince Edward Island, 550 University Ave, Charlottetown, PE, C1A 4P3, Canada. Tel.: +1 902620 5062; fax: +19026205053.

E-mail address: crevie@upei.ca (C.W. Revie). wild salmon populations (Bjørn et al., 2001; Krkošek et al., 2007; Marty et al., 2010). In particular, young sea-faring wild salmon and sea trout may be exposed to sea lice sources from fish farms (Gargan et al., 2003; Heuch et al., 2005). Over the past decade salmon farms in Northern Europe and Chile have relied on a range of veterinary medicines, applied as in-feed or bath treatments, to control lice infestation levels (Sevatdal et al., 2005; Lees et al., 2008a). This has successfully driven down infections on farmed salmon populations with many control programmes achieving a low prevalence of infestation and lice abundances of less than one adult female per fish (Heuch et al., 2009; Heuch et al., 2011-this issue). The use of such medicines is not only expensive but comes with environmental concerns, as well as increasing evidence that lice populations are becoming tolerant to such treatments (Denholm et al., 2002; Fallang et al., 2004; Sevatdal et al., 2005; Bravo et al., 2008; Lees et al., 2008b). There is a need to better understand the epidemiology of lice infections on farms and to conserve the use of medicines if they are 
to remain effective (Fallang et al., 2005; Lees et al., 2008c; Westcott et al., 2008).

Over the past decade mathematical modelling has increasingly been used as a means to better understand the transmission of aquatic pathogens (Reno, 1998; McCallum et al., 2004; Murray, 2009; Green, 2010). Work in this area has included the consideration of sea lice population dynamics. A number of studies have focused on potential interactions between sea lice from wild and farmed sources (Murray and Gillibrand, 2006; Krkošek et al., 2006; Foreman et al., 2009), while a few have specifically modelled the biological development of lice populations in laboratory (Tucker et al., 2002; Stien et al., 2005) or field (Revie et al., 2005; Krkošek et al., 2009) settings.

The Hardangerfjord in the south-west of Norway supports a large number of production units and is an important salmon producing area where coordinated sea lice control is widely practised (Heuch et al., 2009). A three year Hardangerfjord project was initiated in 2004 to better understand the dynamics of sea lice populations over a wide area. By 2007 a large body of data had become available on sea lice populations from different salmon farms and how these populations were being controlled (Heuch et al., 2009). This communication reports on the epidemiological patterns of infection found on farms in the Hardangerfjord and explores the adaptation of a mathematical population model to explore the interaction between $L$. salmonis infections and treatment during spring and autumn stocked production cycles.

\section{Materials and methods}

\subsection{Hardangerfjord lice infection data}

The Hardanger Fish Health Network (HFN) has operated since 2004 in the Hardangerfjord on the south-west coast of Norway where there is a high density of salmon farms. This network was a key partner in the Hardangerfjord Salmon Lice Project which had the overall goal of understanding the complex interaction of hosts, parasites, environment and fish farms (Heuch et al., 2009). ${ }^{1}$ In total 16 of the 18 fish farming companies, controlling around $95 \%$ of the farmed fish population in the fjord, participated in the project with an aim of keeping mean lice abundance below agreed levels, particularly during the wild smolt run in May.

Throughout each production cycle, farms in the Hardangerfjord provided stocking information, together with sea lice counts and treatment data to the HFN. Sea lice counts were collected according to guidelines provided in standard sampling protocols. This enabled abundance, measured as the mean number of lice found on sampled fish (Bush et al., 1997), and sea lice treatment interventions to be monitored across the fjord on a continuous basis. In addition dedicated counting teams collected detailed counts of lice on farmed fish between April and September each year. Data supplied to the HFN by each farm were cross-checked against data collected by the counting teams. Where discrepancies arose, farms were asked by the HFN to check their own records and the correct information was identified. Farm stocking, lice counts and treatment data were available for 69 salmon farms in the Hardangerfjord between 2004 and 2007, although not all farms were stocked every year.

The data were analysed to create a profile of lice abundance and treatment on every farm throughout each production cycle. Most farms practised a single year class stocking pattern with either spring or autumn stocking, followed by a fallowing period. Two characteristic sea lice infestation profiles were developed; one for sites that stocked in the spring and one for sites that stocked in the autumn. Mixed year class production cycles, and those where it was not possible to

\footnotetext{
${ }^{1}$ See also http://www.nina.no/Aktuelt/Artikkel/tabid/945/smid/873/ArticleID/422/ Default.aspx.
}

determine the year class of the smolts, were discounted for the purpose of creating these profiles.

It has previously been shown that salmon farms in the inner fjord generally have a lower abundance of salmon lice (Heuch et al., 2009). In the data set under consideration in this study a majority of sites were located in the inner fjord area for both the spring and autumn stocked groups, though the percentage of inner fjord sites (70\%; 19 of $\mathrm{N}=27$ ) in the spring group was higher than was the case for the autumn stocked group (54\%; 13 of $\mathrm{N}=24$ ).

\subsection{SLiDESim model for lice infections}

The SLiDESim (Sea Lice Difference Equation Simulation) infection model is based on a mathematical representation of $L$. salmonis populations on farmed fish. Its application to lice infestation on Scottish farms has been described in detail by Revie et al. (2005). The model consists of six compartmental "stages". The first compartment/ stage includes the egg and the two planktonic stages. From this first compartment lice move to the infective copepodid and chalimus I-IV compartmental stage. Following varying periods of biological development lice leave the chalimus compartment and develop to the preadult and then to the adult compartmental stages. A separate compartmental stage is assigned to gravid females as this gives rise to the egg and planktonic stages and completes the life-cycle. An external compartmental stage is included to represent the flow of external copepodids which migrate in to the infective copepodid/ chalimus compartmental stage of the life-cycle model. This external infective pressure is necessary to initiate infection on fish and to represent on-going external infestation pressure from sources such as neighbouring farms or wild salmonids. Each compartment represents lice abundance and is modelled using a delay differential equation to ensure that population stages take account of the different biological development times. The key mathematical equations for the life cycle between the infective copepodid, chalimus, pre-adult and gravid female stages follow from those given in Revie et al. (2005)

$$
\begin{aligned}
& \frac{d L_{1}(t)}{d t}=F(t)-F\left(t-\tau_{1}\right) e^{-b_{1} \tau_{1}}-b_{1}(t) L_{1}(t) \\
& \frac{d L_{2}(t)}{d t}=\eta F\left(t-\tau_{1}\right) e^{-b_{1} \tau_{1}}-\eta F\left(t-\tau_{1}-\tau_{2}\right) e^{-b_{1} \tau_{1}-b_{2} \tau_{2}}-b_{2}(t) L_{2}(t)
\end{aligned}
$$

$$
\begin{aligned}
\frac{d L_{3}(t)}{d t}= & \eta F\left(t-\tau_{1}-\tau_{2}\right) e^{-b_{1} \tau_{1}-b_{2} \tau_{2}} \\
& -\eta F\left(t-\tau_{1}-\tau_{2}-\tau_{3}\right) e^{-b_{1} \tau_{1}-b_{2} \tau_{2}-b_{3} \tau_{3}}-b_{3}(t) L_{3}(t)
\end{aligned}
$$

$\frac{d L_{4}(t)}{d t}=\eta F\left(t-\tau_{1}-\tau_{2}-\tau_{3}\right) e^{-b_{1} \tau_{1}-b_{2} \tau_{2}-b_{3} \tau_{3}}-b_{4}(t) L_{4}(t)$

where $L_{1}, L_{2}, L_{3}$ and $L_{4}$ are the number of lice per fish in the chalimus, pre-adult female, adult female and gravid female stages respectively; $\tau_{1}, T_{2}$ and $\tau_{3}$ are the times spent in the chalimus, pre-adult and adult stages respectively; $b_{1}, b_{2}, b_{3}$ and $b_{4}$ are the mortality rates in the chalimus, pre-adult, adult female and gravid female stages respectively; F represents the population feedback and external infection pressure; and $\eta$ is the fraction of the chalimus population that develop into females.

The average periods of development for chalimus, pre-adult, adult and egg to chalimus used in the model were 15, 20, 10 and 20 days respectively, based on mean water temperature (Tucker et al., 2000). A 50:50 ratio of female to male adults was adopted and gravid females were assumed to exponentially decline with a half-life of 12 days. It is recognised that laboratory studies indicate development rates to be affected by temperature and a theoretical outline indicating how such variability could be modelled has been proposed (Stien et al., 2005). However, previous investigations using the model and including 
temperature time-dependence has shown that seasonal variation in temperature produced no discernable effect at farm population level (Revie et al., 2003), though it is generally the case that the level of variability in sea water temperatures in Norway exceeds that seen in Scottish sea lochs (Heuch et al., 2003).

Previous versions of the model for sea lice infections on fish in Scottish farms (Revie et al., 2005; Robbins et al., 2010) have been extended to take account of important features associated with farming practises in the Hardangerfjord. Most importantly, separate models were developed for (i) farms stocked with smolts in the spring and those stocked in the autumn, and (ii) farms which used both infeed and bath treatments in the same production cycle to reflect the practise used in the majority of farms in the HFN.

\subsection{Treatment efficacy}

Treatment efficacy is quite different for bath and in-feed veterinary medicines. Bath treatments are modelled in the SLiDESim infection model as previously reported; where it is assumed that when no tolerance issues are known to exist an instantaneous knock-down efficacy of $95 \%$ across all stages present on the fish is applied. The topical products used were deltramethrin (Alphamax ${ }^{\mathrm{TM}}$, Pharmaq) and cypermethrin (Betamax ${ }^{\mathrm{TM}}$, Novartis), both synthetic pyrethroids, with around twice as many Alphamax ${ }^{\mathrm{TM}}$ treatments being applied during the period under study in the Hardangerfjord. The only in-feed treatment used was emamectin benzoate (SLICE ${ }^{\mathrm{TM}}$, Schering-Plough Animal Health) with a similar total number of treatments over the period as was the case for Alphamax ${ }^{\mathrm{TM}}$. In studying the application of SLICE ${ }^{\mathrm{TM}}$ on Scottish farms, evidence emerged of an exponential decline for the first 28 days to $0.2 \%$ and $0.7 \%$ of lice levels present at the start of the treatment, for chalimus and mobiles respectively (Lees et al., 2008b). The decline is typically followed by a gradual recovery until a point of no effect after 70 days. While detailed estimates for SLICE ${ }^{\mathrm{TM}}$ efficacy on Norwegian farms were not available, the Scottish results are similar to those reported in British Columbia (Saksida et al., 2007) and their adoption thus seems reasonable. If the minimum lice count is $m$ on day $28, \varepsilon$ is the efficacy, and an exponential decline and recovery are assumed, this yields Eq. (1)

$(1-\varepsilon)=\left\{\begin{array}{cc}e^{-\lambda_{1} t} & 0 \leq t \leq 28 \\ m e^{\lambda_{2}(t-28)} & 28<t \leq 70 \\ 1 & t>70\end{array}\right.$

which can be solved for estimates of the growth rates $\lambda_{1}, \lambda_{2}$ as shown below:

$$
\begin{aligned}
& \left.e^{-\lambda_{1} t}\right|_{t=28}=m \Rightarrow \lambda_{1}=\frac{-\ln (m)}{28} \\
& m e^{\lambda_{2}(t-28)} \mid t=70=1 \Rightarrow \lambda_{2}=\frac{-\ln (m)}{42} .
\end{aligned}
$$

The value of $m$ is determined from the percentage reduction of lice counts and using Eq. (2) estimates for $\lambda_{1}$ and $\lambda_{2}$ are obtained.

\section{Results}

Fig. 1a shows the profile of lice infestation on farms that were stocked in the spring. The lice per fish represent the mean monthly abundance for the three stages shown between May of the first calendar year of production and December of the second, based on 27 production cycles from 23 farms. The autumn profile (Fig. 1b) is based on 24 production cycles from 21 farms and shows mean monthly lice abundances between October of the first year of production and May of the third calendar year.

Both profiles were based on a 20 month production cycle and the graphs also show the proportion of farms treated with either in-feed or topical sea lice treatments in each month. The proportion of farms treated varies from month to month with $50 \%$ of the farms being treated in peak months and in particular in December. This reflects the different treatment practises among sites despite a policy of synchronised treatment being in place. Only sea lice treatments that were recorded by either the farm or the dedicated counting teams were included in the profiles; however some sudden drops in lice counts suggest that a limited number of additional treatments may have been given during the course of these production cycles.

It can be seen that spring and autumn stocked farms have different patterns of sea lice counts on salmon. Spring stocked sites increased counts toward the end of the first year and on average remained at over 1.5 mobiles per fish thereafter, whereas autumn stocked sites averaged lower levels (around 0.5 mobiles per fish) throughout most of the production cycle until the autumn of the second year when they rapidly escalated. For spring stocked farms in-feed treatments were mostly used to control infections in the first year of production although a substantial number of production cycles also included bath treatments. In the latter half of the production cycles on spring stocked farms only bath treatments were administered. The use of veterinary medicines was somewhat different on autumn stocked farms, where in-feed treatments are used on farms in the first year of the production cycle followed by bath treatments in the second year. Strategic winter delousing in the first year can also be seen, with well over $50 \%$ of the sites carrying out treatments in the December to January period, as recommended by the HFN. However it appears that the impact of these treatments differed between the two types of sites. While the abundance of chalimus and mobile stages on spring stocked sites fell in response to the strategic treatments, they returned to around their pre-treatment levels by February and March respectively. In contrast the reduction in mobiles which followed winter treatments on autumn stocked sites was maintained and levels remained low until September.

Biological parameters are specified within the SLiDESim model to represent the egg and stage survival rates and the external infective pressure arising from the migration of infective copepodids from outside the farm. The model commences the spring stocked production cycle at the end of April, while for autumn stocked production cycles the model starts at the end of October. These modelled start dates are broadly consistent with the time of year when sites are stocked with smolts.

These young fish are initially exposed to free living infective copepodids. Populations of these copepodids may arise from neighbouring farms or passing wild fish external to the farm. The young fish acquire chalimus infections which develop to the pre-adult and adult stages, where gravid females give rise to the first generation of infective on-site copepodids. The growing fish are continuously challenged by successive generations of such copepodids at an estimated average daily rate of infection as indicated by the gravid female to chalimus ratio in Table 1.

In addition to the constant background external challenge the farmed fish can also become infected from an external background pulse of infective copepodids. A short intense pulse may arise from migrating fish populations or the inflow of coastal water containing copepodids (Wallace, 1998). For the Hardangerfjord spring and autumn stocked farms a single pulse of 20 days duration at the end of October significantly improved the fit of both models. The additional daily rate of infection per fish during this pulse is indicated by the background pulse height (Table 1 ).

The remaining parameter estimates were initially adopted from experiences using the SLiDESim model on Scottish farm data (Revie et al., 2002). Refined estimates were obtained using local optimisation searches to enhance the fit between the pattern of counts from the model and the patterns observed on farms. These parameters for spring and autumn stocked production systems are summarised in Table 1.

The results of applying the modified SLiDESim infection model to spring stocked farms after local optimisation of the biological parameters as described above are shown in Fig. 2a. The model is 
a

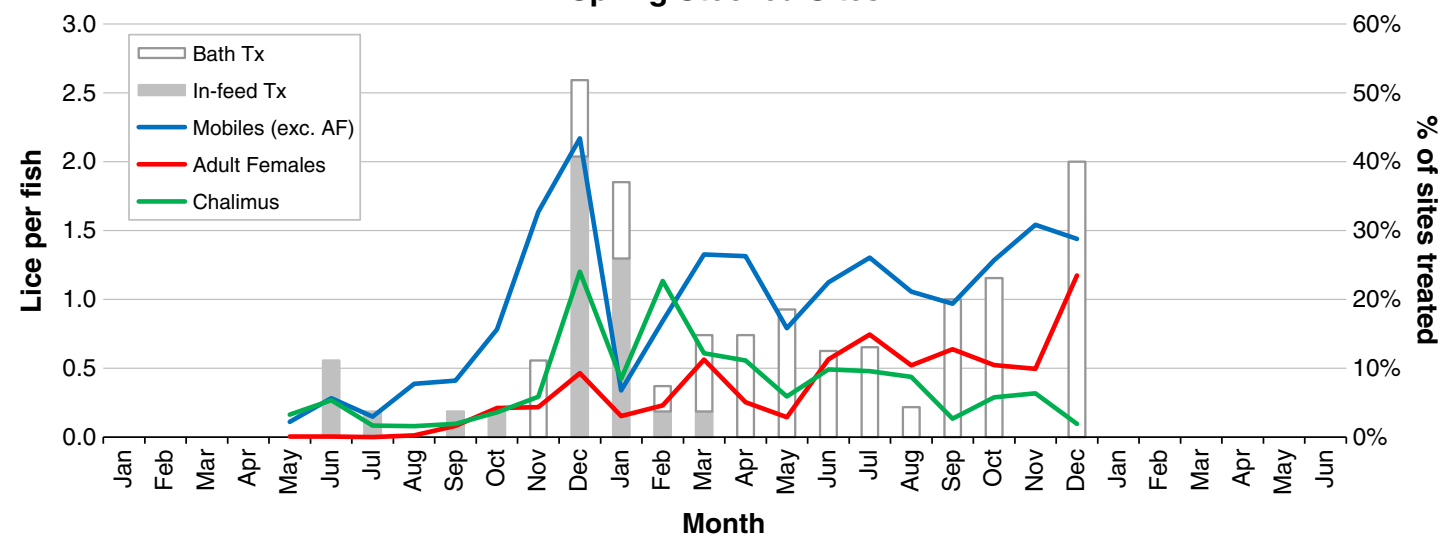

b

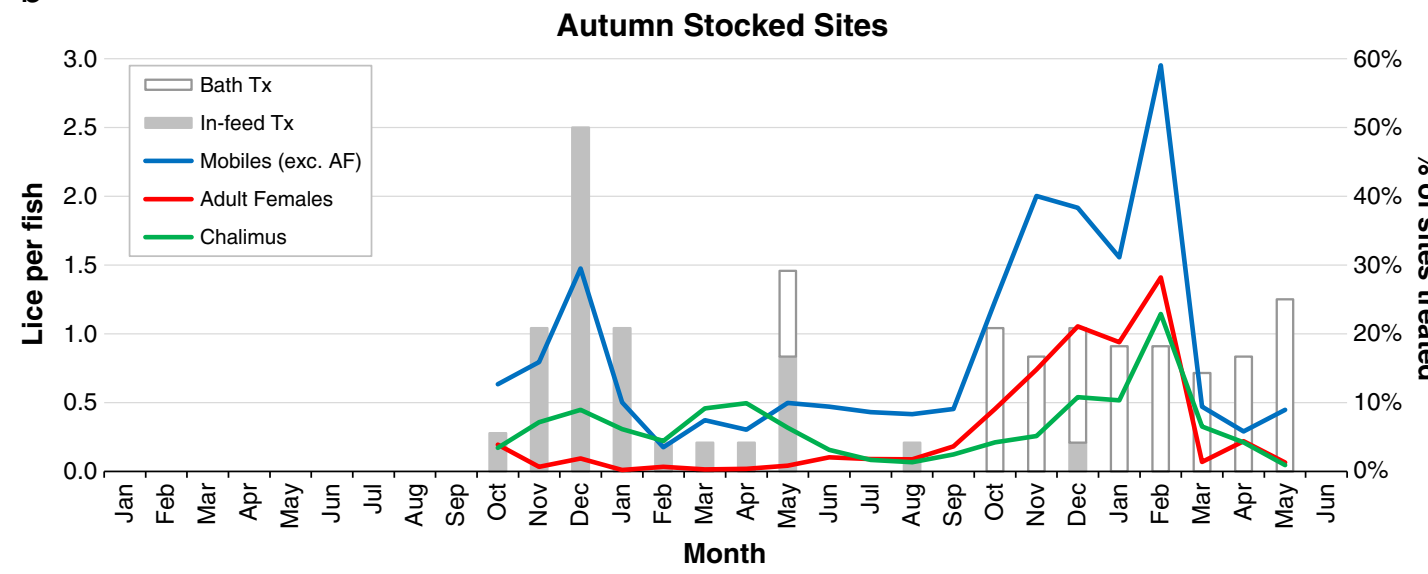

Fig. 1. Profiles of the abundance of lice infestation by stage on spring (a) and autumn (b) stocked farms observed in the Hardangerfjord for the period 2004 to 2007 together with treatment summaries per month.

able to replicate the first major peak (circa November/December) and the trough at the end of the first year and beginning of the second year. Subsequent observed peaks (March and July) and troughs (May and August) are not reproduced by the model but the overall trend of increasing numbers of mobiles throughout the second year is indicated. Given the low absolute level of lice counts the model reflects the general observed mobile pattern but not the detail.

For autumn stocked farms the results from the SLiDESim infection model when compared to the observed mobiles are more encouraging than for spring stocked farms (Fig. 2b). Following the broad agreement between model and observed counts on the early first peak in December at the end of the first year, the same general pattern is obtained until the end of the second year. In particular the model captures the notable observed increase in mobile counts October to December of the second year. However the observed increased mobile levels are seen to continue until February before steeply declining, whereas the model counts rapidly declined after December. Once again when making comparisons between observed and model counts, caution is required as the population density values are small and subject to measurement uncertainty.

\section{Discussion}

The assimilation of data on farm stocking practise, sea lice counts and treatment interventions on 44 farms in the Hardangerfjord from 2004 to 2007 facilitated the creation of 'average patterns' of sea lice infestations. Patterns for spring and autumn stocked farms were seen to be different. Spring stocked sites were associated with increased counts toward the end of the first year and on average these counts remained high, whereas autumn stocked sites were associated with

Table 1

Biological parameters adopted in the Hardangerfjord SLiDESim infection model to describe the different lice dynamics for spring and summer stocked farms

\begin{tabular}{|c|c|c|c|}
\hline Parameter & Spring stocked & Autumn stocked & Description \\
\hline Survival of chalimus & 0.911 & 0.906 & $\begin{array}{l}\text { Probability an infective copepodid/chalimus stage louse survives } \\
\text { to become mobile. }\end{array}$ \\
\hline Survival of mobiles & 0.750 & 0.711 & Probability a mobile stage louse survives to become an adult. \\
\hline Gravid female to chalimus ratio $\left(\right.$ day $^{-1}$ ) & 1.889 & 0.720 & $\begin{array}{l}\text { Effective number of infective copepodids/chalimus returned to the } \\
\text { system per day from gravid females. }\end{array}$ \\
\hline External infection $\left(\right.$ fish $^{-1}$, day $\left.^{-1}\right)$ & 0.278 & 0.189 & The average rate of arrival of external infective copepodids. \\
\hline Background pulse height $\left(\right.$ fish $^{-1}$, day $^{-1}$ ) & 1.500 & 3.330 & $\begin{array}{l}\text { The additional rate of arrival of infective copepodids during the } \\
\text { single external background pulse. }\end{array}$ \\
\hline
\end{tabular}


a

Spring Stocked Sites

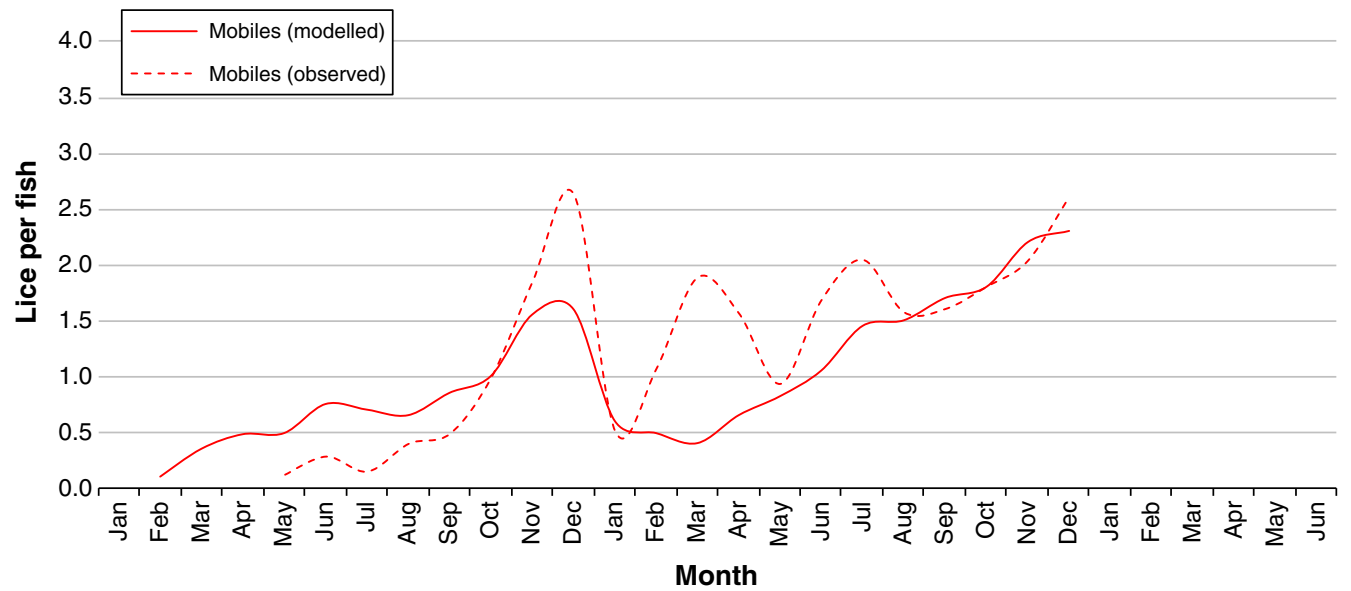

b

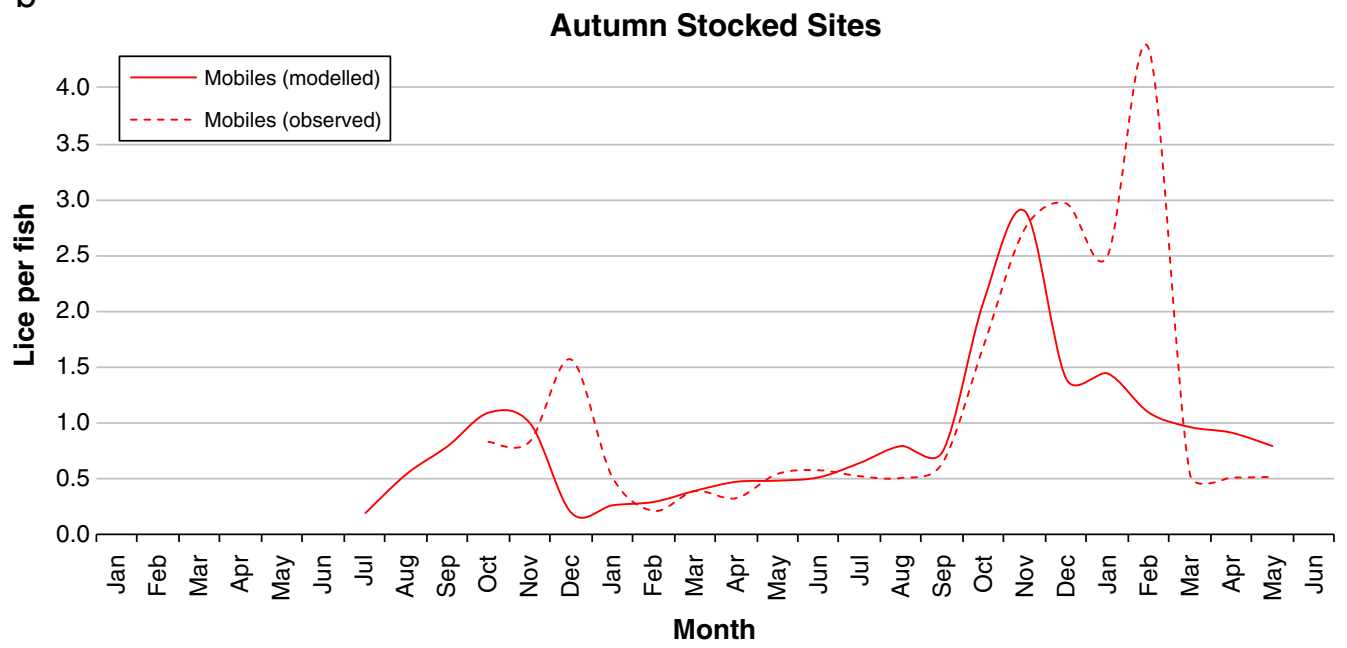

Fig. 2. A comparison of modelled lice abundance from the SLiDESim infection model and the observed abundance of mobile lice infestations on spring (a) and autumn (b) stocked farms observed in the Hardangerfjord for the period 2004 to 2007.

low counts throughout most of the production cycle until the autumn of the second year when they rapidly escalated. There was clear evidence of strategic and extensive use of in-feed and bath veterinary medicines, with in-feed treatments being preferred in the first year of each production system and bath treatments in the second year before harvesting. This pattern of use has its origins in the long withdrawal period set by the Norwegian authorities for SLICE ${ }^{\mathrm{TM}}$ when it was first introduced, and the fact that the price of using in-feed treatments increases as fish become larger. Both withdrawal period and, to a lesser extent, relative costs have changed, but the traditional patterns of medicinal use apparently persisted during the period under study.

The strategic treatments in December-January of the first year of the production cycle appeared to produce different effects on the spring and the autumn stocked fish. In the autumn stocked fish these treatments reduced the abundance of mobile stages from around 1.5 to 0.2 from December to February. The abundances of chalimus and adult females were already below 0.5 and 0.1 respectively, and the intervention appeared to maintain these levels for around six months. It is known that the use of SLICE ${ }^{\mathrm{TM}}$ can significantly lower adult female lice abundance (Olsen, 2005; Heuch et al., 2009), and that the residual effect of treatments can last from two to five months, depending on the re-infestation challenge (Lees et al., 2008b; Saksida et al., 2007). Thus the patterns observed for autumn stocked sites are not surprising. What is more difficult to explain is why a similar level of suppression is not seen in the lice levels on spring stocked sites. These sites use, proportionately, a similar level of SLICE ${ }^{\mathrm{TM}}$ treatments (in addition to a small number of bath treatments) and yet the lice levels quickly rebound after treatment and remain at around 2 mobiles per fish from March onwards. What seems clear is that the level of gravid females present on the spring-stocked fish is notably higher than that seen on the autumn stocked site, perhaps simply due to the additional 6 months that these fish have been in sea water. While the absolute abundance appears low on the spring-stocked sites (at around 0.2-0.4) this still represents a 10-20 fold increase on the levels recorded at the autumnstocked sites and it would appear to be this 'reservoir' of gravid females that generates the relatively rapid re-infestation seen on spring-stocked sites. This has direct relevance to the issue of setting treatment trigger threshold levels; in that the potential for generating re-infestation on a site, rather than any direct impact of fish welfare, may need to be taken into account when such thresholds are being devised (Revie et al., 2009).

Using the sea lice difference equation simulation (SLiDESim) model a range of biological and production parameters were explored to obtain the best fit to the patterns observed on the spring and autumn stocked farms. The modelling took account of the frequency of application and type of treatment practised on the farms.

For models of spring and autumn stocked farms it was found that the same stage development times for chalimus, pre-adult, adult, gravid female and egg to chalimus stages as that used for Scottish farms led to 
broad agreement between observed and predicted mobile counts. The models also worked best when the spring and autumn production cycles had similar survival rates for the chalimus and mobile stages and were initiated 120 days after the beginning and the midpoint of the calendar year respectively. Although no formal sensitivity analyses have been illustrated to address uncertainty in parameter estimates, experience from using the model does indicate it to be sensitive and small changes in parameters can lead to different sea lice profiles. This is consistent with sea lice populations being opportunistic and having the capacity to increase and diminish in very short periods of time unlike many hostparasite systems where a stable equilibrium exists.

In the present data set, the spring stocked and autumn stocked farms were approximately equally distributed on the inner and outer areas of the fjord, with slightly more autumn stocked farms being located in the outer area. All else being equal, one would therefore expect that the two groups of farms had about the same lice abundances or that the autumn stocked group might have slightly more lice due simply to being in the outer (more saline) areas, which have been reported to have higher lice levels (Bricknell et al., 2006; Heuch et al., 2009). The fact that the opposite was observed indicates that the reason that spring stocked farms appear to be infested with more lice, and exhibit poorer winter delousing results, is not due to their siting.

The results show that modelling gives an approximate fit to the observed Hardangerfjord lice abundance patterns. However for spring stocked farms the model was unable to produce the oscillatory pattern of counts observed following the first major peak in the production cycle, even after localised numerical searches were undertaken to refine the biological parameters. For autumn stocked farms the mobile lice counts obtained using the model broadly resembled the observed counts and suggested that a systems modelling approach has the potential to predict farm outcomes.

A much higher daily rate of gravid female eggs converting to chalimus and a higher daily external infection rate from other farms or wild fish were required for the spring stocked model than was the case for the autumn stocked model. This would translate to a higher survival rate of eggs on a female louse to the settlement of copepodid and development to chalimus in the case of spring stocking. This phase includes the free living period of the parasite's life, and suggests that if the model is capturing real biological or physical differences, the survival of the planktonic stages is better and the probability of a successful infection higher for lice infecting spring stocked salmon. It is possible that this reflects the fact that stocking farms in spring would be more aligned to the natural 'stocking' of the marine environment by sea trout and salmon smolts in spring (Jonsson, 1985; Shearer, 1992), and that the lice may be better adapted to this part of their host's ecology.

Additional external pulses of infective copepodids were required in October for both autumn and spring stocked farms, but the magnitude of the pulse had to be much greater for the autumn stocked farm model. In contrast to the differences in the infection/survival rate parameters noted above, it is not obvious what biological and/or environmental factors might require this increased 'background' pulse for autumn stocked farms. It may simply be the case that this was the most mathematically convenient parameter to provide the model with a reasonable fit to the unusually high level of observed mobile lice in the winter of the second year for these autumn stocked sites.

Clearly the observed infestation patterns on farms is multifactorial and requires careful timing of external pulses and the identification of a credible set of biological parameters to obtain viable patterns for mobile counts on both spring and autumn stocked farms. Before the model can be used to evaluate optimal treatment strategies there is a need to further understand parameters indicated by the model and their reconciliation to the underlying biological and environmental processes. This would include the re-examination of the role of temperature on development rates, the impact of salinity on survival from one stage to another, the ratio of male to female lice in different stages, the age-related resistance of fish to infection, and the variability associated with the distribution of lice on fish when the prevalence of infection is low in farm management systems where treatment is administered in response to an increase in lice counts. The modelling approach offers a unique way forward for the evaluation of the impact of different treatment strategies, as reported for cypermethrin by Robbins et al. (2010), the scope for investigating the dynamics of lice populations in relation to the sensitivity of biological determinants, and the ability to explore the onset of resistance to therapeutants.

\section{Acknowledgements}

This work was funded by the Fisheries and Aquaculture Research Fund and the Norwegian Research Council as "The Hardangerfjord Salmon Lice Project" from 2004 to 2010, under project numbers 163869 and 178833. Thanks are due to the fish farmers, HFN staff and participants in the sea lice counting teams who collected much of the data used in this study.

\section{References}

Bjørn, P.A., Finstad, B., Kristoffersen, R., 2001. Salmon lice infection of wild sea trout and Arctic char in marine and freshwaters: the effects of salmon farms. Aquac. Res. 32, 947-962.

Bravo, S., Sevatdal, S., Horsberg, T.E., 2008. Sensitivity assessment of Caligus rogercresseyi to emamectin benzoate in Chile. Aquaculture 282, 7-12.

Bricknell, I.R., Dalesman, S.J., O'Shea, B., Pert, C.C. Mordue Luntz, A.J., 2006. Effect of environmental salinity on sea lice Lepeophtheirus salmonis settlement success. Dis. Aquat. Org. 71, 201-212.

Bush, A.O., Lafferty, K.D., Lotz, J.M., Shostak, A.W., 1997. Parasitology meets ecology on its own terms: Margolis et al. revisited. J. Parasitol. 83, 575-583.

Costello, M., 2009. The global economic cost of sea lice to the salmonid farming industry. J. Fish Dis. 32, 115-118.

Denholm, I., Devine, G.J., Horsberg, T.E., Sevatdal, S., Fallang, A., Nolan, D.V., Powell, R., 2002. Analysis and management of resistance to chemotherapeutants in salmon lice, Lepeophtheirus salmonis (Copepoda: Caligidae). Pest Manage. Sci. 58, 528-536.

Fallang, A., Ramsay, J.M., Sevatdal, S., Burka, J.F., Jewess, P., Hammell, L., Horsberg, T.E., 2004. Evidence for occurrence of an organophosphate-resistant type of acetylcholinesterase in strains of sea lice (Lepeophtheirus salmonis Krøyer). Pest Manage. Sci. $60,1163-1170$.

Fallang, A., Denholm, I., Horsberg, T.E., Williamson, M.S., 2005. Novel point mutation in the sodium channel gene of pyrethroid-resistant sea lice Lepeophtheirus salmonis (Crustacea: Copepoda). Dis. Aquat. Org. 65, 129-136.

Foreman, M.G.G., Czajko, P., Stucchi, M., Guo, M., 2009. A finite volume model simulation for the Broughton Archipelago, Canada. Ocean Model. 30, 29-47.

Gargan, P.G., Tully, O., Poole, W.R., 2003. The Relationship Between Sea Lice Infestation, Sea Lice Production and Sea Trout Survival in Ireland, 1992-2001. In: Mills, D. (Ed.), Salmon on the Edge. Blackwell Scientific Publications, Oxford, UK, pp. 119-135. 307 pp.

Green, D.M., 2010. A strategic model for epidemic control in aquaculture. Prev. Vet. Med. 94, 119-127.

Heuch, P.A., Revie, C.W., Gettinby, G., 2003. A comparison of epidemiological patterns of salmon lice (Lepeophtheirus salmonis) infections in Norway and Scotland. J. Fish Dis. 26, 539-551.

Heuch, P.A., Bjørn, P.A., Finstad, B., Holst, J.C., Asplin, L., Nilsen, F., 2005. A review of the Norwegian 'National Action plan against salmon lice on salmonids': the effect on wild salmonids. Aquaculture 246, 79-92.

Heuch, P.A., Stigum, O., Malkenes, R., Revie, C.W., Gettinby, G., Baillie, M., Lees, F., Finstad, B., 2009. Temporal and spatial variations in lice numbers on salmon farms in the Hardanger fjord 2004-2006. J. Fish Dis. 32, 89-100.

Heuch, P.A., Gettinby, G., Revie, C.W., 2011. Counting sea lice on Atlantic salmon farms - Emperical and theoretical observations. Aquaculture 320, 149-153 (this issue).

Jonsson, B., 1985. Life history patterns of freshwater resident and sea-run migrant brown trout in Norway. Trans. Am. Fish. Soc. 114, 182-194.

Krkošek, M., Lewis, M.A., Morton, A., Frazer, L.N., Volpe, J.P., 2006. Epizootics of wild fish induced by fish farms. Proc. Natl Acad. Sci. 103, 15506-15510.

Krkošek, M., Ford, J.S., Morton, A., Lele, S., Myers, R.A., Lewis, M.A., 2007. Declining wild salmon populations in relation to parasites from farm salmon. Science 318 , $1772-1775$.

Krkošek, M., Morton, A., Volpe, J.P., Lewis, M.A., 2009. Sea lice and salmon population dynamics: effects of exposure time for migratory fish. Proc. R. Soc. B 276 (1668), 2819-2828.

Lees, F., Gettinby, G., Revie, C.W., 2008a. Changes in epidemiological patterns of sea lice infestation on farmed Atlantic salmon (Salmo salar L) in Scotland between 1996 and 2006. J. Fish Dis. 31, 251-262.

Lees, F., Baillie, M., Gettinby, G., Revie, C.W., 2008b. The efficacy of emamectin benzoate against infestations of Lepeophtheirus salmonis on farmed Atlantic salmon (Salmo salar L) in Scotland between 2002 and 2006. PLoS ONE 3 (2), e1549.F. 
Lees, F., Baillie, M., Gettinby, G., Revie, C.W., 2008c. Factors associated with changing efficacy of emamectin benzoate against infestations of Lepeophtheirus salmonis on Scottish salmon farms. J. Fish Dis. 31, 947-951.

Marty, G.D., Saksida, S.M., Quinn, T.J., 2010. Relationship of farm salmon, sea lice, and wild salmon populations. PNAS 107, 22599-22604.

McCallum, H., Kuris, A., Harvell, C.D., Lafferty, K.D., Smith, G.W., Porter, J., 2004. Does terrestrial epidemiology apply in marine systems? Trends Ecol. Evol. 19, 585-591.

Murray, A.G., 2009. Using simple models to review the application and implications of different approaches used to simulate transmission of pathogens among aquatic animals. Prev. Vet. Med. 88, 167-177.

Murray, A.G., Gillibrand, P.A., 2006. Modelling dispersal of salmon lice in Loch Torridon, Scotland. Mar. Pollut. Bull. 53, 128-135.

Olsen, R.S., 2005. Prosjekt Vinteravlusning i Hardangerfjorden 2004/2005. Report Hardanger Fiskehelsenettverk, Eikelandsosen, Norway. 17 pp.

Reno, P.W., 1998. Factors involved in the dissemination of disease in fish populations. J. Aquat. Anim. Health 10, 160-171.

Revie, C.W., Gettinby, G., Treasurer, J.W., Grant, A.N., Reid, S.W.J., 2002. Sea lice infestation on Atlantic salmon and the use of ectoparasitic treatments on commercial farms in Scotland. Vet. Rec. 151, 753-757.

Revie, C.W., Gettinby, G., Treasurer, J.W., Wallace, C., 2003. Identifying epidemiological factors affecting sea lice (Lepeophtheirus salmonis) abundance on Scottish salmon farms using general linear models. Dis. Aquat. Org. 57, 85-95

Revie, C.W., Robbins, C., Gettinby, G., Kelly, L., Treasurer, J.W., 2005. A mathematical model of the growth of sea lice, Lepeophtheirus salmonis, populations on farmed Atlantic salmon, Salmo salar L., in Scotland and its use in the assessment of treatment strategies. J. Fish Dis. 28, 603-613.

Revie, C., Dill, L., Finstad, B., Todd, C., 2009. Sea Lice Working Group Report: Report from the Technical Working Group on Sea Lice of the Salmon Aquaculture Dialogue (A Sub-group of the Working Group on Salmon Disease): NINA Special Report, 39. $117 \mathrm{pp}$.
Robbins, C., Gettinby, G., Lees, L., Baillie, M., Wallace, C., Revie, C.W., 2010. Assessing topical treatment interventions on Scottish salmon farms using a sea lice (Lepeophtheirus salmonis) population model. Aquaculture 306, 191-197.

Saksida, S., Constantine, J., Karreman, G.A., Donald, A., 2007. Evaluation of sea lice abundance levels on farmed Atlantic salmon (Salmo salar L.) located in the Broughton Archipelago of British Columbia from 2003 to 2005. Aquac. Res. 38 219-231.

Sevatdal, S., Copley, L., Wallace, C., Jackson, D., Horsberg, T.E., 2005. Monitoring of the sensitivity of sea lice (Lepeophtheirus salmonis) to pyrethroids in Norway, Ireland and Scotland using bioassays and probit modelling. Aquaculture 244, 19-27.

Shearer, W.M., 1992. The Atlantic Salmon. Natural History, Exploitation and Future Management. Fishing News Books, Oxford.

Stien, A., Bjørn, P.A., Heuch, P.A., Elston, D., 2005. Population dynamics of salmon lice Lepeophtheirus salmonis on Atlantic salmon and sea trout. Mar. Ecol. Prog. Ser. 290, 263-275.

Tucker, C.S., Sommerville, C., Wootten, R., 2000. The effect of temperature and salinity on the settlement and survival of copepodids of Lepeophtheirus salmonis (Krøyer, 1837) on Atlantic salmon, Salmo salar L. J. Fish Dis. 23, 309-320.

Tucker, C.S., Norman, R., Shinn, A.P., Bron, J.E., Sommerville, C., Wootten, R., 2002. A single cohort time delay model of the life-cycle of the salmon louse Lepeophtheirus salmonis on Atlantic salmon Salmo salar. Fish Pathol. 37, 107-118.

Wallace, C., 1998. Possible causes of salmon lice Lepeophtheirus salmonis (Krøyer, 1837) infections on farmed Atlantic salmon, Salmo salar L., in a Western Norwegian fjordsituated fish farm: Implications for the design of regional management strategies. Cand. Scient. thesis, University of Bergen, Bergen, Norway.

Westcott, J.D., Stryhn, H., Burka, J.F., Hammell, K.L., 2008. Optimization and field use of a bioassay to monitor sea lice Lepeophtheirus salmonis sensitivity to emamectin benzoate. Dis. Aquat. Org. 79, 119-131. 